\title{
Development and Initial Validation of the Coalitional Mate Retention Inventory
}

\author{
Michael N. Pham • Nicole Barbaro • Todd K. Shackelford
}

Published online: 4 October 2014

(C) Springer International Publishing 2014

\begin{abstract}
Mate retention behaviors are designed to reduce the likelihood of partner infidelity and relationship termination. Measures of mate retention historically have focused on individual mate retention-behaviors that individuals perform alone. The current research explores coalitional mate retention (CMR) - mate retention with assistance from allies. Using an act nomination procedure, we constructed the CMR Inventory (CMRI) to assess specific CMR behaviors. In study 1 , participants $(n=100)$ provided open-ended responses in which they nominated CMR behaviors. In study 2, participants $(n=387)$ provided frequency reports on the $44 \mathrm{CMR}$ behaviors identified in study 1 . We conducted principal component analyses to guide construction of the CMRI, which assesses seven components of CMRI: manipulation (e.g., "got my partner drunk to see what my partner said"), praise (e.g., "said nice things about me when my partner and other people were around"), vigilance (e.g., "observed how my partner acted around people interested in my partner"), monopolizing time (e.g., "accompanied my partner to a party"), therapy (e.g., "told my partner how much I liked my partner"), gifts (e.g., "told me what gifts my partner wanted"), and violence (e.g., "hit someone who was flirting with my partner"). Discussion highlights the limitations of focusing exclusively on individual mate retention and the importance of considering alliances when researching mate retention.
\end{abstract}

M. N. Pham $(\bowtie)$

Department of Psychology, Oakland University, 107 Pryale Hall, Rochester, MI 48309, USA

e-mail:mnpham@oakland.edu

N. Barbaro

Department of Psychology, University of Pittsburgh, Pittsburgh, PA, USA

T. K. Shackelford

Department of Psychology, Oakland University, 112 Pryale Hall, Rochester, MI 48309, USA
Keywords Mate retention - Coalitional mate retention Inventory $\cdot$ Friends $\cdot$ Maintenance behaviors

Romantic infidelity is accompanied by various costs. Infidelity is a leading cause of separation and divorce (Allen and Atkins 2012). Those who suspect or discover their partner's infidelity may suffer from major depression, anxiety, and relationship dissatisfaction (Betzig 1989; Cano and O'Leary 2000). Individuals who commit infidelity may contract sexually transmitted diseases from an extra-pair partner, thereby placing their regular partner at risk of contracting those diseases. A man whose regular partner commits sexual infidelity is at risk of investing resources into offspring to whom he is genetically unrelated.

Given the costs of partner infidelity, individuals perform mate retention behaviors to reduce the likelihood of partner infidelity. A widely used mate retention instrument is the Mate Retention Inventory (MRI; Buss 1988; Buss et al. 2008), which measures performance frequencies of specific mate retention behaviors. Behaviors assessed by the MRI include those predicted and found to be sexually differentiated, according to evolutionary psychological theory. For example, men more than women display material resources and deploy violence to retain a mate, whereas women more than men enhance their physical appearance and use sexual inducements to retain a mate (Buss 1988; Buss and Shackelford 1997). Virtually, all (102 of 104) behaviors included in the MRI are individual-level behaviors - behaviors that individuals perform alone (i.e., without assistance from others).

Guided by social exchange theory, Stafford and Canary (1991) developed the relational maintenance strategy measure - an inventory of relational maintenance behaviors that focus on maintaining relationship stability through coordinated efforts between partners. Behaviors in this inventory focus on cooperation (e.g., "share in the joint responsibilities that face us") and relationship equity (e.g., "help equally with tasks 
that need to be done"). One of the five tactics in this inventory-network - includes behaviors that use social networks to maintain relationship stability (e.g., "like to spend time with our same friends," "focus on common friends and affiliations"). However, Stafford and Canary did not explore specific behaviors that friends perform to assist in promoting relationship stability. The current research investigates specific behaviors that comprise coalitional mate retention (CMR), defined here as mate retention with assistance from allies (i.e., friends).

\section{Documented Cases of Coalitional Mate Retention}

Nonhuman animals that recruit allies for CMR can overcome limitations of individual mate retention. For example, in lions, a coalition of males is more successful than a single male at defending sexual access to a female against rivals (Grinnell et al. 1995; Schaller 1972). Macaque males may form coalitions to overpower higher-ranking males to secure sexual access to fertile females (Bissonnette et al. 2011). Males of other species also sometimes form alliances with other males to defend sexual access to females as has been documented in cheetahs (Caro 1994), chimpanzees (Watts 1998; Nishida and Hosaka 1996), and dunnocks (Davies 1992).

Historically, humans have practiced CMR. For example, kings recruited guards to protect their harem (Lad 2011). The inclusion of two items in the MRI — "had my friends check up on my partner" and "got my friends to beat up someone who was interested in my partner"- suggests that humans sometimes perform CMR (Buss 1988; Buss et al. 2008). The inventory developed by Stafford and Canary (1991) provides an indirect evidence of CMR: Maintaining social networks shared by romantic partners is important for maintaining stable relationships. Individuals whose partner has sex with their friend - relative to with a stranger or with an enemyfeel most betrayed by their partner (Shackelford and Buss 1996), providing indirect evidence that individuals understand that one should not pursue a friend's romantic partner. Indeed, trustworthiness is important for maintaining friendships (Cottrell et al. 2007; Vigil 2007). Unlike some nonhuman species in which males cooperatively breed with females (see Watts 1998), humans do not typically tolerate allies having sex with their partner.

\section{Benefits of Coalitional Mate Retention}

CMR can overcome the costs of excessive individual mate retention. Individuals who perceive their partner to be overbearing, excessively jealous, and mistrustful (i.e., they perceive that their partner performs excessive mate retention) also report greater relationship dissatisfaction and sometimes terminate the relationship as a result (Guerrero et al. 1995). Individuals can reduce their partner's perception of excessive mate retention by employing CMR. Individuals who use CMR can decrease the likelihood of their partner's infidelity without appearing overbearing to their partner. For example, individuals may recruit allies to accompany their partner to a social gathering to ensure that their partner does not flirt with others, while simultaneously appearing trusting to their partner because they are absent.

CMR can overcome time (e.g., restrictive work schedules) and geographic (e.g., long-distance relationships) restrictions of individual mate retention. For example, individuals may be less likely to commit infidelity during a trip away from their partner if, during that trip, they are accompanied by their partner's friends. Similar to vigilance-related behaviors in the MRI, individuals can employ CMR to perform proxy vigilance through their allies.

Individuals can boost their mating desirability to their partner with assistance from allies, thereby decreasing the likelihood of their partner's infidelity. Individuals mated to a less (versus more) desirable partner are more likely to terminate the relationship or commit infidelity (Shackelford and Buss 1997). Individuals can ask their friend to advertise their mating qualities for them (e.g., your friend says positive things about you), thereby avoiding the costs of appearing narcissistic if they bragged about themselves and validating those advertisements by providing corroborative evidence from friends.

\section{Costs of Coalitional Mate Retention}

CMR has potential costs. Those who recruit a same-sex ally for CMR risk their ally poaching their partner-luring their partner away or having sex with their partner. Kings were aware of potential mate poaching by guards and, therefore, recruited eunuchs - instead of sexually functional men - to police their harem (Lad 2011). Two items included in the MRI - "told my same-sex friends how much my partner and I were in love" and "refused to introduce my partner to my same-sex friends" - indicate that individuals are aware that same-sex friends are potential mate poachers.

Those who recruit an opposite-sex ally for CMR risk being the target of their ally's mate poaching (Mogilski and Wade 2013). The majority of men, and some women, are sexually attracted to their opposite-sex friends (Kaplan and Keys 1997) and report uncertainty about sexual boundaries with those friends (Swain 1992). Individuals sometimes befriend opposite-sex friends with the explicit intention of mate poaching (Schmitt and Buss 2001). Some men report that "there wasn't enough sex in our relationship" as a reason for ending an opposite-sex friendship (Bleske-Rechek and Buss 2001). 


\section{Overview of the Current Research}

Despite substantial evidence that friends play important roles in helping to maintain romantic relationships (Canary and Stafford 1992; Stafford and Canary 1991), research has yet to investigate how friends assist in CMR. Here, we develop and provide initial psychometric validation of the Coalitional Mate Retention Inventory (CMRI). In study 1, participants provided open-ended responses in which they nominated CMR behaviors. In study 2, a new sample of participants provided frequency reports on the CMR behaviors identified in study 1 .

\section{Study 1}

Method

\section{Participants and Procedure}

We recruited 100 participants from Facebook. Participants were at least 18 years of age. Participation was anonymous and unrewarded.

Following previous act nomination procedures (Buss and Craik 1983), participants reported up to ten acts that they (or someone they know) asked their friend or relative to do to prevent their partner from becoming interested in someone else. Participants recorded their responses on an online survey host.

\section{Results}

We collected 190 act nominations. We eliminated vague acts (e.g., "asked my friend to help with my relationship") and irrelevant acts (e.g., "I am never jealous") to construct an initial 44-item CMR Inventory for further investigation in study 2 (complete list of acts is available upon request).

\section{Study 2}

Method

\section{Participants}

We recruited from Amazon's Mechanical Turk (MTurk) 387 participants (176 women) in a committed, heterosexual relationship lasting at least 1 year. The mean participant age was 32.1 years $(\mathrm{SD}=9.1)$, and the mean relationship length was 66.0 months $(\mathrm{SD}=88.5)$. Participants reported on interactions with two friends (one man and one woman, see below), each of whom they considered as a good friend, and each of whom they have known for at least 1 year. The mean length of the friendship was 88.7 months $(\mathrm{SD}=90.2)$ with the male friend and 76.6 months $(\mathrm{SD}=89.6)$ with the female friend. We implemented MTurk filters recommended by Peer et al. (2013). MTurk workers who could access had successfully completed at least (1) 500 MTurk jobs and (2) $95 \%$ of their jobs.

\section{Materials}

In line with Simmons et al. (2011), we fully disclose all variables. Participants reported their age, sex, and romantic relationship length. Participants reported the number of miles they lived from their partner, and how often they have sex with their partner during a typical week. Participants completed the Mate Retention Inventory Short Form (MRI-SF), in which they reported on a four-point scale $(0=$ never, $1=$ rarely, $2=$ sometimes, and $3=$ often) how often they performed 38 mate retention behaviors during the past year (Buss et al. 2008). Participants also completed the HEXACO-60, which secures scores on personality traits (Ashton and Lee 2009).

Participants were instructed to think of one heterosexual man and one heterosexual woman, each of whom they considered to be good friend, and each of whom they have known for at least 1 year. For the remainder of the survey, participants answered each question twice: once for their male friend and again for their female friend.

Participants reported their friend's age, the length of their friendship (in months), whether their friend was in a committed or romantic relationship, and whether their friend was friends with their partner. Participants completed the McGill Friendship Questionnaire (Mendelson and Aboud 1999), which assesses friendship quality. Participants completed the 44-item initial CMRI, in which they reported on a four-point scale $(0=$ never, $1=$ rarely, $2=$ sometimes, and $3=$ often) (1) how often they requested their friend to perform each behavior during the past year and (2) how often they believed their friend performed that behavior during the past year. These two frequency reports are not necessarily related. For example, individuals can frequently request a CMR behavior, but their friend never performs the behavior (i.e., their friend disregards the CMR request), or individuals might never request a $\mathrm{CMR}$ behavior, but their friend frequently performs the behavior (i.e., their friend performed an unrequested CMR behavior). Two attention check questions were incorporated into the CMRI: one question asked participants to respond "never" and the other question asked participants to respond "often."

\section{Procedures}

Potential participants viewed an advertisement for this study on MTurk's job listings. Those interested in participating were 
provided a link to a consent form. Those who electronically signed the consent form could access the survey, and those who did not sign were exited from the study. Participants who correctly answered the attention check questions were compensated \$4.00. Responses from participants who failed the attention check questions ( 31 of 387 or $8.0 \%$ ) were excluded from analyses.

\section{Results}

Participants reported for each CMR behavior how often they requested that behavior from (1) their male friend $(\alpha=0.97$ across all items) and (2) their female friend $(\alpha=0.97)$ and the frequency with which that behavior was performed by (3) their male friend $(\alpha=0.96)$ and (4) their female friend $(\alpha=$ $0.96)$. Because participants and their friends were heterosexual, some CMR behaviors only applied to same-sex friends (e.g., "seduced my partner to help me test my partner's faithfulness to me" might only apply to same-sex friends). Thus, we used each participant's sex to generate CMR behavior request frequencies for (5) their same-sex friend $(\alpha=0.97)$ and (6) their opposite-sex friend ( $\alpha=0.97)$ and CMR behavior performance frequencies for (7) their same-sex friend $(\alpha=$ $0.95)$ and (8) their opposite-sex friend $(\alpha=0.96)$. In total, there were eight versions of the CMRI.

We conducted principal component analyses (PCAs, followed by direct oblimin rotation) on each of the eight versions of the CMRI. For each version, we extracted and retained components with an eigenvalue greater than 1.0 (Kaiser-Guttman criterion; see Jackson 1993). The PCA for each of the eight versions produced five or six components. After comparing PCA results from all eight versions, the male friend's CMR performance version provided a useful starting point for constructing the CMRI because this version produced the most interpretable components (see Table 1 for component loadings and labels for male friend's CMR performance; analyses of all eight PCAs are available upon request). For this version, each item had a component loading of at least 0.30 on at least one component. Because the development of the CMRI is in its early stages, we adopted a liberal loading requirement (0.30) and, therefore, none of the 44 items were eliminated.

First, we assigned each item to the component onto which it loaded most highly. Then, we moved a few items from one component to another because of their conceptual resemblance with items in the new components. We moved "included my partner in group activities" and "studied with my partner" to component 4 (monopolizing time). We moved "followed my partner around" to component 3 (vigilance). We moved "reassured my partner that I liked my partner," "listened to my partner's relationship concerns," and "told my partner that cheating was wrong" to component 5 (therapy). There is a compelling theoretical reason to group violence-
Table 1 Component loadings on CMR performed by male friend (principal components analysis, direct oblimin rotation)

Loading

Component 1: manipulation

Tried to "hook up" my partner with someone else to see what my partner did

Told me if he saw my partner cheating on me

Seduced my partner to help me test my partner's faithfulness to me

Got my partner drunk to see what my partner said

Got my partner drunk to see what my partner did

Hit someone who was flirting with my partner

Told me if my partner was cheating on me

Wore revealing clothing around my partner

Fought someone who was interested in my partner

Flirted with my partner to help me test my partner's faithfulness to me

Intimidated someone who was interested in my partner

Said bad things about me to see how my partner would react

Said negative things about my romantic relationship to my partner to see if my partner would defend our romantic relationship

Followed my partner around $\quad 0.47$

Studied with my partner $\quad 0.47$

Talked to my partner to learn if my partner was $\quad 0.44$ interested in someone else

Told my partner that cheating was wrong $\quad 0.44$

Asked my partner if my partner found other people attractive $\quad 0.38$

Component 2: praise

Said nice things about me when my partner and other people $\quad 0.83$ were around

Said positive things about me to my partner $\quad 0.75$

Mentioned me in conversation around my partner when I $\quad 0.73$ wasn't around

Said positive things about me to my partner's friends $\quad 0.60$

Chatted with my partner $\quad 0.55$

Included my partner in group activities $\quad 0.42$

Component 3: vigilance

Observed if my partner was interested in someone else $\quad-0.82$

Observed how my partner acted around people interested in my -0.75 partner

Reassured my partner that I liked my partner $\quad-0.55$

Observed if my partner mentioned me during conversations $\quad-0.52$ with others

Mentioned a story to others that involved me and my $\quad-0.44$ partner to remind others that my partner was in a relationship

Observed if my partner was wearing gifts that I gave my partner

Component 4: monopolizing time Went out with my partner $\quad-0.85$

Made plans with my partner for a get-together $\quad-0.83$

Accompanied my partner to a party $\quad-0.69$

Asked my partner for help with a task (e.g., home $\quad-0.68$ maintenance, yard work, school work)

Drove my partner home

$-0.66$

Spent time with my partner when I wasn’t present
0.84

0.82 7 38 . 3 烈 12

\section{2} s.

\section{.44}


Table 1 (continued)

\begin{tabular}{lc}
\hline & Loading \\
\hline Kept my partner company & -0.64 \\
Listened to my partner's relationship concerns & -0.46 \\
Component 5: therapy & 0.60 \\
Asked my partner if my partner wanted to marry me & 0.61 \\
Asked my partner how serious my partner was about me & 0.57 \\
Asked my partner if my partner loved me & 0.43 \\
Told my partner how much I liked my partner & -0.45 \\
Component 6: gifts & -0.42 \\
Told me what gifts my partner wanted & \\
\hline Told me my partner's size (e.g., dress, ring) so & \\
\hline
\end{tabular}

related CMR behaviors into a unique component: Men more than women employ violence as mate retention (Buss 1988; Buss et al. 2008; Buss and Shackelford 1997). Thus, we moved three items to a new violence component: "fought someone who was interested in my partner," "hit someone who was flirting with my partner," and "intimidated someone who was interested in my partner" (see Appendix for item placements in the final CMRI).

\section{Components of Coalitional Mate Retention}

The manipulation component includes behaviors in which an ally deceives the partner into admitting (e.g., "got my partner drunk to see what my partner said") or demonstrating (e.g., 'tried to 'hook up' my partner with someone else to see what my partner did") the partner's propensity to commit infidelity. The praise component includes behaviors in which an ally says positive things to the partner and to others (e.g., "said nice things about me when my partner and other people were around"), thereby increasing the romantic partnership's desirability. The vigilance component includes behaviors in which an ally watches the partner's behavior (e.g., "observed how my partner acted around people interested in my partner"). The monopolizing time component includes behaviors in which an ally spends time with the partner (e.g., "accompanied my partner to a party"). The therapy component includes behaviors in which an ally strengthens the romantic partnership by repairing relationship problems and listening to relationship concerns (e.g., "told my partner how much I liked my partner"). The gifts component includes behaviors in which an ally secures information about appropriate gifts for the partner (e.g., "told me what gifts my partner wanted"). The violence component includes behaviors in which violence is employed against potential mate poachers (e.g., "hit someone who was flirting with my partner").
Relationships between MRI Tactics and CMRI Tactics

It is not clear whether individuals who employ more CMR will also employ more individual mate retention (i.e., concurrent strategies) or less individual mate retention (i.e., compensatory strategies). If CMR functions primarily to overcome constraints associated with individual mate retention, then individual mate retention and CMR may be concurrent strategies because individuals may be attempting to exhaust possible strategies to reduce the likelihood of partner infidelity or relationship defection. If CMR functions primarily to disguise jealousy and mistrust, then individual mate retention and CMR may be compensatory strategies because individual mate retention, not CMR, overtly demonstrates jealousy.

We investigated the relationship between these two classes of mate retention strategies. First, we computed tactic scores by computing the mean scores across items within each tactic from the MRI-SF and from the CMRI. Then, we correlated each tactic score from the MRI-SF with each tactic score from the CMRI. The CMRI and MRI-SF use identical four-point scales (never, rarely, sometimes, and often), and both measure performance frequencies over the past year (see Table 2). Of the 72 significant correlations, 71 were positive, suggesting that individuals who deploy more individual mate retention also deploy more CMR.

\section{Sex Differences in Coalitional Mate Retention}

Table 3 presents the results of tests for sex differences in CMR performance frequencies. Men (relative to women) more frequently recruit their female friends to determine appropriate gifts for their partner. Female friends (relative to male friends) more frequently provide relationship therapy. Unexpectedly, both men and women more frequently recruit their female friend (relative to their male friend) to deploy violent CMR (e.g., hitting, fighting, and intimidating potential poachers). To verify that our sample was not unusual, relative to samples recruited for other mate retention studies, we investigated whether the sexes differ in the violence tactic from the MRI-SF (complete analyses of sex differences for all MRI-SF tactics are available upon request). Consistent with previous research (Buss 1988; Buss and Shackelford 1997), men $(M=1.25, \mathrm{SD}=0.52)$ relative to women $(M=1.13, \mathrm{SD}=0.42)$ more frequently perform individual mate retention involving violence$t(348)=2.18, p<0.05$. Thus, despite the unexpected sex difference in violent CMR, our sample is similar to samples from previous mate retention studies.

\section{Discussion}

The current research aimed to develop and provide initial psychometric validation for an inventory that assesses 
Table 2 Zero-order correlations between CMRI tactics (columns) and MRI tactics (rows)

\begin{tabular}{|c|c|c|c|c|c|c|c|c|}
\hline & $\alpha$ & Gifts & Therapy & Monopolize & Vigilance & Praise & Manipulation & Violence \\
\hline Vigilance & 0.50 & 0.09 & $0.16^{* *}$ & 0.06 & $0.20 * *$ & 0.03 & $0.13^{*}$ & $0.14^{*}$ \\
\hline Concealment of mate & 0.67 & $0.18^{* *}$ & $0.24 * *$ & -0.02 & $0.20 * *$ & -0.00 & $0.28 * *$ & $0.39 * *$ \\
\hline Monopolization of time & 0.80 & $0.25 * *$ & $0.26^{* *}$ & 0.07 & $0.20 * *$ & -0.02 & $0.30 * *$ & $0.37 * *$ \\
\hline Jealousy induction & 0.74 & $0.21 * *$ & $0.25 * *$ & 0.01 & $0.16^{* *}$ & -0.08 & $0.35 * *$ & $0.34 * *$ \\
\hline Punish mate's infidelity threat & 0.53 & $0.19 * *$ & $0.17 * *$ & 0.07 & $0.18 * *$ & 0.00 & $0.21 * *$ & $0.17 * *$ \\
\hline Emotional manipulation & 0.66 & $0.15 * *$ & $0.13^{*}$ & 0.01 & 0.11 & -0.09 & $0.25 * *$ & $0.31 * *$ \\
\hline Commitment manipulation & 0.48 & $0.24 * *$ & $0.31 * *$ & $0.11^{*}$ & $0.26^{* *}$ & 0.04 & $0.27 * *$ & $0.32 * *$ \\
\hline Derogation of competitors & 0.70 & 0.09 & 0.10 & 0.04 & 0.07 & -0.00 & $0.13^{*}$ & $0.15^{*}$ \\
\hline Resource display & 0.59 & $0.12 *$ & $0.13 *$ & $0.14 * *$ & $0.13^{*}$ & $0.15^{* *}$ & 0.05 & 0.01 \\
\hline Sexual inducements & 0.20 & $0.14^{*}$ & $0.15 * *$ & 0.05 & $0.20 * *$ & 0.05 & $0.15^{* *}$ & $0.17 * *$ \\
\hline Appearance enhancement & 0.60 & 0.09 & 0.11 & $0.13^{*}$ & $0.14^{*}$ & $0.18 * *$ & -0.03 & -0.03 \\
\hline Love and care & 0.65 & 0.04 & 0.03 & 0.10 & 0.07 & 0.10 & -0.03 & -0.05 \\
\hline Submission and debasement & 0.76 & $0.12 *$ & $0.18 * *$ & 0.02 & $0.20 * *$ & 0.01 & 0.10 & $0.13^{*}$ \\
\hline Verbal possession signals & 0.63 & 0.10 & $0.18^{* *}$ & 0.10 & $0.15^{* *}$ & $0.13^{*}$ & 0.05 & 0.06 \\
\hline Physical possession signals & 0.77 & -0.02 & -0.05 & 0.03 & 0.03 & 0.09 & -0.06 & $-0.12 *$ \\
\hline Possessive ornamentation & 0.73 & $0.21 * *$ & $0.22^{* *}$ & 0.09 & $0.22^{* *}$ & 0.00 & $0.25 * *$ & $0.25 * *$ \\
\hline Derogation of mate & 0.58 & 0.07 & 0.08 & -0.03 & 0.08 & -0.01 & $0.18 * *$ & $0.23 * *$ \\
\hline Intrasexual threats & 0.85 & $0.28 * *$ & $0.22^{* *}$ & 0.10 & $0.23 * *$ & 0.04 & $0.24 * *$ & $0.28 * *$ \\
\hline Violence against rivals & 0.72 & $0.17 * *$ & $0.23 * *$ & 0.00 & $0.13^{*}$ & 0.01 & $0.33 * *$ & $0.37 * *$ \\
\hline$\alpha$ & & 0.72 & 0.86 & 0.88 & 0.82 & 0.81 & 0.93 & 0.85 \\
\hline
\end{tabular}

$* p<0.05 ; * * p<0.01$

$n=324 . \alpha=$ Cronbach's alpha reliability

coalitional mate retention (CMR) using a balance of data- and theory-driven methods. The CMRI includes 44 behaviors that individuals deploy with assistance from allies to reduce the likelihood of partner infidelity or relationship defection. The components extracted from the CMRI range from negative, cost-inflicting behaviors (e.g., manipulation) to positive, benefit-provisioning behaviors (e.g., therapy).
Because this is a new inventory, replication of the current research is especially warranted. We recommend that future research recruit participants using diverse recruitment methods. Buhrmester et al. (2011) found that participants comprising MTurk samples differed demographically (e.g., age, ethnicity) from participants comprising standard internet samples or college samples. Future research could replicate

Table 3 Mean performance frequencies (standard deviations) of each CMR tactic, separated by participant's sex and by friend's sex

\begin{tabular}{|c|c|c|c|c|c|c|c|c|}
\hline & \multicolumn{3}{|c|}{ Male participants $(n=189)$} & \multicolumn{3}{|c|}{ Female participants $(n=154)$} & \multirow{2}{*}{$\begin{array}{l}\text { Male friends } \\
\text { Diff. }^{b}\end{array}$} & \multirow{2}{*}{$\begin{array}{l}\text { Female friends } \\
\text { Diff. }^{b}\end{array}$} \\
\hline & Male friends & Female friends & Diff. $^{\mathrm{a}}$ & Male friends & Female friends & Diff. $^{\mathrm{a}}$ & & \\
\hline Gifts & $1.70(0.78)$ & $1.73(0.73)$ & -0.59 & $1.65(0.84)$ & $1.30(0.58)$ & $6.52 * * *$ & 0.55 & $5.89 * * *$ \\
\hline Therapy & $1.77(0.64)$ & $1.92(0.62)$ & $-3.55 * * *$ & $1.70(0.68)$ & $1.78(0.62)$ & $-2.29 *$ & 0.97 & $2.10^{*}$ \\
\hline Monopolize & $1.95(0.63)$ & $2.41(0.81)$ & $-8.37 * * *$ & $2.18(0.71)$ & $1.76(0.57)$ & $7.28 * *$ & $-3.09 * *$ & $8.37 * * *$ \\
\hline Vigilance & $1.71(0.64)$ & $1.93(0.73)$ & $-5.36 * * *$ & $1.63(0.60)$ & $1.76(0.70)$ & $-3.22 * * *$ & 1.23 & $2.25^{*}$ \\
\hline Praise & $2.61(0.69)$ & $2.14(0.73)$ & $8.56^{* * *}$ & $2.62(0.80)$ & $2.02(0.76)$ & $10.51 * * *$ & -0.20 & 1.55 \\
\hline Manipulation & $1.34(0.56)$ & $1.53(0.56)$ & $-8.62 * * *$ & $1.24(0.43)$ & $1.35(0.50)$ & $-4.87 * * *$ & 1.91 & $2.96^{* *}$ \\
\hline Violence & $1.38(0.60)$ & $2.00(0.67)$ & $12.54 * * *$ & $1.23(0.52)$ & $2.06(0.70)$ & $-14.32 * * *$ & $2.35^{*}$ & -0.87 \\
\hline
\end{tabular}

${ }^{*} p<0.05 ; * * p<0.01 ; * * * p<0.001$

${ }^{\text {a }}$ Repeated measures $t$ tests comparing male friends against female friends (within-sex participants)

${ }^{\mathrm{b}}$ Between-subjects $t$ tests comparing male participants against female participants (within-sex friends) 
the current research using different recruitment methods, including in-person surveys.

We suspect potential cultural differences in CMR. For example, adolescents who self-identify as more collective (versus those who identify as more individualistic) are closer to their same-sex friends and are more sensitive to those friends' needs (Verkuyten 1996), suggesting that unrequested same-sex CMR may be deployed more frequently in collectivist cultures than in individualistic cultures. Future research could recruit multicultural samples to explore cultural differences in CMR.

We did not investigate CMR with assistance from relatives. Relatives - compared to friends - can sometimes generate stronger alliances. For example, when forming coalitions, individuals are more likely to receive help from relatives than from non-relatives (Ackerman and Kenrick 2008). Thus, individuals who assist relatives receive benefits resulting from genetic relatedness. Additionally, CMR with relatives - compared to CMR with friends - carries different costs. For example, it is less likely that an individual would sabotage their opposite-sex relative's relationship-relative to their opposite-sex friend's relationship-because of romantic feelings for the target. Furthermore, relatives-compared to friends-may perform more unrequested CMR. CMR may be perceived more explicitly as a favor with friends than with relatives (i.e., reciprocal altruism; Trivers 1971), which may motivate individuals to perform more unrequested CMR for relatives than for friends. Future research might investigate differences in CMR involving friends versus relatives.

The CMRI may provide an important tool for research on long-distance, romantic relationships. In the USA, as many as one million people annually are in a long-distance relationship, up to $50 \%$ of first-year college students are in a long-distance relationship, and $10 \%$ of job relocations cause romantic relationships to become long-distance relationships (reviewed in Aylor 2003). Additionally, work schedules and career choices are causing more couples to live apart (Armour 1998; reviewed in Aylor 2003). The MRI might produce uninterpretable results for such logistically constrained relationships. For example, two of the mate retention tactics assessed by the MRI are monopolizing a partner's time and remaining vigilant about a partner's whereabouts. However, individuals who spend time apart from their partner because of logistics (e.g., long-distance relationships, work schedules, business trips) would score lower on these two tactics, but not necessarily because they lack motivation to perform mate retention. In fact, the time individuals spend apart from their partner is the time they cannot account for their partner's behaviors and is, therefore, the time during which there may be greatest motivation to perform mate retention (Dainton and Aylor 2001; McKibbin et al. 2011; Pham and Shackelford 2013; Shackelford et al. 2007, 2002).

This research explores the intersection of two ubiquitous features of human life: mate retention behavior and coalitional behavior. Interest in mate retention behavior has penetrated several research domains, including personality psychology (McKibbin et al. 2014), sexual behavior (Goetz et al. 2005), and ovulatory cycling (Gangestad et al. 2002). The current research adds to this literature by highlighting the importance of mate retention with assistance from allies.

Acknowledgments We would like to thank Jennifer Vonk and Virgil Zeigler-Hill for their thoughtful feedback on this research project.

\section{Appendix. Coalitional Mate Retention Inventory}

Instructions: The following is a list of behaviors that your friend might perform to help strengthen your romantic relationship. For example, your friend might perform some behaviors to ensure that your romantic partner is not being unfaithful to you when you are absent (e.g., your friend accompanies your partner to a party). Your friend also might perform behaviors that may appear harmful to your relationship (e.g., your friend flirts with your partner), but your friend is actually trying to help you by testing your romantic partner's commitment to you. As you read through the items, it is important to remember that each item refers to a behavior that your friend might perform with the intention of helping you strengthen your romantic relationship.

In the left column, please indicate how frequently your friend performed the following behaviors during the past 1 year with the intention of helping you strengthen your relationship. You might not be certain how often your friend performs each behavior during your absence, so provide your best guess for how often you think it occurs.

In the right column, please indicate how frequently you explicitly asked your friend to perform the following behaviors during the past 1 year with the intention of helping you strengthen your romantic relationship.

Note that your responses in the left column might be unrelated to your responses in the right column. For example, your friend might frequently perform a behavior ("often" in the left column), even though you never asked your friend ("never" in the right column).

$$
\begin{aligned}
& 0=\text { Never } \\
& 1=\text { Rarely } \\
& 2=\text { Sometimes } \\
& 3=\text { Often }
\end{aligned}
$$




\section{Manipulation}

- $\quad$ Talked to my partner to learn if my partner was interested in someone else.

- $\quad$ Told me if he saw my partner cheating on me.

- Told me if my partner was cheating on me.

- Asked my partner if my partner found other people attractive.

- Flirted with my partner to help me test my partner's faithfulness to me.

- Got my partner drunk to see what my partner said.

- Got my partner drunk to see what my partner did.

- Seduced my partner to help me test my partner's faithfulness to me.

- Wore revealing clothing around my partner.

- Said bad things about me to see how my partner would react.

- Tried to "hook up" my partner with someone else to see what my partner did.

- Said negative things about my romantic relationship to my partner to see if my partner would defend our romantic relationship.

\section{Praise}

- Said nice things about me when my partner and other people were around.

- Said positive things about me to my partner.

- Mentioned me in conversation around my partner when I wasn't around.

- Said positive things about me to my partner's friends.

- Chatted with my partner.

- $\quad$ Reassured my partner that I liked my partner.

\section{Vigilance}

- Observed if my partner was interested in someone else.

- Observed how my partner acted around people interested in my partner.

- Observed if my partner mentioned me during conversations with others.

- Mentioned a story to others that involved me and my partner to remind others that my partner was in a relationship.

- Observed if my partner was wearing gifts that I gave my partner.

- Followed my partner around.

\section{Monopolizing time}

- Studied with my partner.

- Went out with my partner.

- Made plans with my partner for a get-together.
- Accompanied my partner to a party.

- Asked my partner for help with a task (e.g., home maintenance, yard work, school work).

- Drove my partner home.

- Spent time with my partner when I wasn’t present.

\section{Therapy}

- Told my partner that cheating was wrong.

- Kept my partner company.

- Listened to my partner's relationship concerns.

- Asked my partner if my partner wanted to marry me.

- Asked my partner how serious my partner was about me.

- Asked my partner if my partner loved me.

- $\quad$ Told my partner how much I liked my partner.

- Included my partner in group activities.

\section{Gifts}

- $\quad$ Told me what gifts my partner wanted.

- $\quad$ Told me my partner's size (e.g., dress, ring) so I could buy my partner appropriately-sized gifts.

\section{Violence}

- Hit someone who was flirting with my partner.

- Fought someone who was interested in my partner.

- Intimidated someone who was interested in my partner.

\section{References}

Ackerman, J. M., \& Kenrick, D. T. (2008). The costs of benefits: helprefusals highlight key trade-offs of social life. Personality and Social Psychology Review, 12, 118-140.

Allen, E. S., \& Atkins, D. C. (2012). The association of divorce and extramarital sex in a representative US sample. Journal of Family Issues, 33, 1477-1493.

Armour, S. (1998). Married...with separation: more couples live apart as careers put miles between them. USA Today, C2-C4.

Ashton, M. C., \& Lee, K. (2009). The HEXACO-60: a short measure of the major dimensions of personality. Journal of Personality Assessment, 91, 340-345.

Aylor, B. (2003). Maintaining long-distance relationships. In D. J. Canary \& M. Dainton (Eds.), Maintaining relationships through communication: relationship, contextual, and cultural variations (pp. 127140). New York: Lawrence Erlbaum Associates.

Betzig, L. (1989). Causes of conjugal dissolution: a cross-cultural study. Current Anthropology, 30, 654-676.

Bissonnette, A., Bischofberger, N., \& van Schaik, C. P. (2011). Mating skew in Barbary macaque males: the role of female mating synchrony, female behavior, and male-male coalitions. Behavioral Ecology and Sociobiology, 65, 167-182.

Bleske-Rechek, A. L., \& Buss, D. M. (2001). Opposite sex friendship: sex differences and similarities in initiation, selection, and dissolution. Personality and Social Psychology Bulletin, 27, 1310-1323. 
Buhrmester, M., Kwang, T., \& Gosling, S. D. (2011). Amazon's Mechanical Turk a new source of inexpensive, yet high-quality, data? Perspectives on Psychological Science, 6, 3-5.

Buss, D. M. (1988). From vigilance to violence: tactics of mate retention in American undergraduates. Ethology and Sociobiology, 9, 291-317.

Buss, D. M., \& Shackelford, T. K. (1997). From vigilance to violence: mate retention tactics in married couples. Journal of Personality and Social Psychology, 72, 346-361.

Buss, D. M., Shackelford, T. K., \& McKibbin, W. F. (2008). The Mate Retention Inventory-Short Form (MRI-SF). Personality and Individual Differences, 44, 322-334.

Buss, D. M., \& Craik, K. H. (1983). The act frequency approach to personality. Psychological Review, 90, 105-126.

Canary, D. J., \& Stafford, L. (1992). Relational maintenance strategies and equity in marriage. Communications Monographs, 59, 243-267.

Cano, A., \& O'Leary, K. D. (2000). Infidelity and separations precipitate major depressive episodes and symptoms of nonspecific depression and anxiety. Journal of Consulting and Clinical Psychology, 68, 774-783.

Caro, T. M. (1994). Cheetahs of the Serengeti Plains: group living in an asocial species. Chicago: University of Chicago Press.

Cottrell, C. A., Neuberg, S. L., \& Li, N. P. (2007). What do people desire in others? A sociofunctional perspective on the importance of different valued characteristics. Journal of Personality and Social Psychology, 92, 208-231.

Dainton, M., \& Aylor, B. (2001). A relational uncertainty analysis of jealousy, trust, and maintenance in long-distance versus geographically close relationships. Communication Quarterly, 49, 172-188.

Davies, N. B. (1992). Dunnock behaviour and social evolution. Oxford: Oxford University Press.

Gangestad, S. W., Thornhill, R., \& Garver, C. E. (2002). Changes in women's sexual interests and their partner's mate-retention tactics across the menstrual cycle: evidence for shifting conflicts of interest. Proceedings of the Royal Society of London. Series B: Biological Sciences, 269, 975-982.

Goetz, A. T., Shackelford, T. K., Weekes-Shackelford, V. A., Euler, H. A., Hoier, S., Schmitt, D. P., \& LaMunyon, C. W. (2005). Mate retention, semen displacement, and human sperm competition: a preliminary investigation of tactics to prevent and correct female infidelity. Personality and Individual Differences, 38, 749-763.

Grinnell, J., Packer, C., \& Pusey, A. E. (1995). Cooperation in male lions: kinship, reciprocity or mutualism? Animal Behaviour, 49, 95-105.

Guerrero, L. K., Andersen, P. A., Jorgensen, P. F., Spitzberg, B. H., \& Eloy, S. V. (1995). Coping with the green-eyed monster: conceptualizing and measuring communicative responses to romantic jealousy. Western Journal of Communication, 59, 270-304.

Jackson, D. A. (1993). Stopping rules in principal components analysis: a comparison of heuristical and statistical approaches. Ecology, 74, 2204-2214.

Kaplan, D. L., \& Keys, C. B. (1997). Sex and relationship variables as predictors of sexual attraction in cross-sex platonic friendships between young heterosexual adults. Journal of Social and Personal Relationships, 14, 191-206.

Lad, J. (2011). Panoptic bodies: black eunuchs as guardians of the Topkapi harem. In M. Booth (Ed.), Harem histories: envisioning places and living spaces (pp. 136-176). Durham: Duke University Press.

McKibbin, W. F., Miner, E. J., Shackelford, T. K., Ehrke, A. D., \& Weekes-Shackelford, V. A. (2014). Men's mate retention varies with men's personality and their partner's personality. Personality and Individual Differences, 56, 62-67.

McKibbin, W. F., Starratt, V. G., Shackelford, T. K., \& Goetz, A. T. (2011). Perceived risk of female infidelity moderates the relationship between objective risk of female infidelity and sexual coercion in Humans (Homo sapiens). Journal of Comparative Psychology, 125, 370-373.

Mendelson, M. J., \& Aboud, F. E. (1999). Measuring friendship quality in late adolescents and young adults: McGill Friendship Questionnaires. Canadian Journal of Behavioural Science, 31, $130-132$.

Mogilski, J. K., \& Wade, T. J. (2013). Friendship as a relationship infiltration tactic during human mate poaching. Evolutionary Psychology, 11, 926-943.

Nishida, T., \& Hosaka, K. (1996). Coalition strategies among adult male chimpanzees of Mahale Mountains, Tanzania. In T. Nishida \& L. F. Marchant (Eds.), Great ape societies (pp. 114-134). Cambridge: Cambridge University Press.

Peer, E., Vosgerau, J., \& Acquisti, A. (2013). Reputation as a sufficient condition for data quality on Amazon Mechanical Turk. Behavior Research Methods. doi:10.3758/s13428-013-0434-y. Advance online publication.

Pham, M. N., \& Shackelford, T. K. (2013). The relationship between objective sperm competition risk and men's copulatory interest is moderated by partner's time spent with other men. Human Nature, $24,476-485$

Schaller, G. B. (1972). The Serengeti lion: a study of predator-prey relations. Chicago: University of Chicago Press.

Schmitt, D. P., \& Buss, D. M. (2001). Human mate poaching: tactics and temptations for infiltrating existing mateships. Journal of Personality and Social Psychology, 80, 894-917.

Shackelford, T. K., \& Buss, D. M. (1996). Betrayal in mateships, friendships, and coalitions. Personality and Social Psychology Bulletin, $22,1151-1164$.

Shackelford, T. K., \& Buss, D. M. (1997). Anticipation of marital dissolution as a consequence of spousal infidelity. Journal of Social and Personal Relationships, 14, 793-808.

Shackelford, T. K., Goetz, A. T., McKibbin, W. F., \& Starratt, V. G. (2007). Absence makes the adaptations grow fonder: proportion of time apart from partner, male sexual psychology, and sperm competition in humans (Homo sapiens). Journal of Comparative Psychology, 121, 214-220.

Shackelford, T. K., LeBlanc, G. J., Weekes-Shackelford, V. A., BleskeRechek, A. L., Euler, H. A., \& Hoier, S. (2002). Psychological adaptation to human sperm competition. Evolution and Human Behavior, 23, 123-138.

Simmons, J. P., Nelson, L. D., \& Simonsohn, U. (2011). False-positive psychology: undisclosed flexibility in data collection and analysis allows presenting anything as significant. Psychological Science, 22, 1359-1366.

Stafford, L., \& Canary, D. J. (1991). Maintenance strategies and romantic relationship type, gender and relational characteristics. Journal of Social and Personal Relationships, 8, 217-242.

Swain, S. O. (1992). Men's friendships with women: intimacy, sexual boundaries, and the informant role. In P. M. Nardi (Ed.), Men's friendships (pp. 153-171). Thousand Oaks, CA: Sage.

Trivers, R. L. (1971). The evolution of reciprocal altruism. Quarterly Review of Biology, 46, 35-57.

Verkuyten, M. (1996). Culture and gender differences in the perception of friendship by adolescents. International Journal of Psychology, 31, 207-217.

Vigil, J. M. (2007). Asymmetries in the friendship preferences and social styles of men and women. Human Nature, 18, 143-161.

Watts, D. P. (1998). Coalitionary mate guarding by male chimpanzees at Ngogo, Kibale National Park, Uganda. Behavioral Ecology and Sociobiology, 44, 43-55. 